Research Article

\title{
Mechanical Response and Structure Optimization of Nanomodified Asphalt Pavement
}

\author{
Wenjun Gu ${ }^{1},{ }^{1}$ Yao Tian, ${ }^{2}$ and Xuanyu Zhang ${ }^{3}$ \\ ${ }^{1}$ Institute for Advanced Study, 7835 Muirfield Court, Potomac, MD 20854, USA \\ ${ }^{2}$ Shandong Hi-Speed Group, Jinan, Shandong 250098, China \\ ${ }^{3}$ Shandong Hi-Speed Infrastructure Construction Co. Ltd., Jinan, Shandong 250098, China \\ Correspondence should be addressed to Wenjun Gu; gu_wenjun@hotmail.com
}

Received 6 May 2021; Revised 5 July 2021; Accepted 16 August 2021; Published 26 August 2021

Academic Editor: Jiaolong Ren

Copyright (C) 2021 Wenjun Gu et al. This is an open access article distributed under the Creative Commons Attribution License, which permits unrestricted use, distribution, and reproduction in any medium, provided the original work is properly cited.

\begin{abstract}
Nanomaterials are widely used in the preparation of modified asphalt because they can improve the high-temperature performance of matrix asphalt and have achieved good engineering results. However, the existing research mainly focuses on the material analysis and formula development of nanomodified asphalt and has not yet been involved in the mechanical response of the nanomodified asphalt pavement structure. The mechanical response contains the horizontal tensile stress and the vertical compressive stress of $\mathrm{SiO}_{2} \mathrm{modified}$ asphalt pavement. It is unable to propose the matching pavement structure combination for the unique material characteristics of nanomodified asphalt, which leads to the increase of the possibility of pavement diseases and material waste. Hence, considering that semirigid base is the most widely used base type in China, two different structural models of nanomodified asphalt pavement are established according to the current specifications. The effects of pavement thickness, material type, and pavement design parameters on the mechanical response of nanomodified asphalt pavement are analyzed, and then the principle of optimal mechanical performance is taken and the optimal combination of nanomodified asphalt pavement structure is proposed.
\end{abstract}

\section{Introduction}

In recent years, nanotechnology has been widely used in asphalt modification, which has obvious effect on improving the hightemperature performance of asphalt [1-5]. Caputo et al. introduced the properties of nanoparticles in an easy to review their use in bitumen and asphalt preparation and Silica, ceramic, clay, other oxides, and inorganic nanoparticles and discussed the framework of their use in bitumen and asphalt preparation for various scopes [6]. Li et al. found that the addition of nanomaterials could dramatically enhance the properties of an asphalt material such as viscoselasticity, high-temperature properties, and the resistances to aging, fatigue, and moisture [7]. Sun et al. studied improving base asphalt performance at both high temperature and low temperature in nanomaterials and polymers as composite modifiers to address the lowtemperature performance of base asphalt binder [8]. Ma et al. droved $\mathrm{TiO}_{2}$ nanoparticles application into the pavement and present an experimental investigation of performances and automobile exhaust purification of asphalt and its mixture modified by nano- $\mathrm{TiO}_{2}$ [9]. $\mathrm{Hu}$ et al. formulated thermochromic hot-mixing asphalt (HMA) mixture by doping thermochromic powder and/or nano- $\mathrm{TiO}_{2}$ scatters at different concentrations into traditional asphalt mixture [10]. Hu et al. investigated the feasibility of $\mathrm{TiO}_{2}$ waterborne epoxy resin as fog seal and exhaust degradation material in the asphalt pavement by adding a commercial anatase/rutile mixed-phase nano- $\mathrm{TiO}_{2}$ [11]. Li et al. investigated the effects of surface-modified inorganic nanoparticle nano- $\mathrm{ZnO}$ on the physical and ultraviolet aging resistance of bitumen as well as the microstructures of the binders [12]. Karahancer et al. investigated a novel bitumen modification by aluminum oxide $\left(\mathrm{Al}_{2} \mathrm{O}_{3}\right)$ nanoparticle, mixed with the bitumen in three percentages, to enhance the performance of bitumen and hot mix asphalt (HMA) [13]. Sarkar et al. improved the physical and mechanical properties of opengraded friction courses (OGFCs) by addicting the combination of nanosilica (NS) material and alkali resistant (AR) glass fiber [14]. Li et al. used two nanometer microwave absorbers named 
as carbon nanotubes (CNTs) and grapheme to improve the microwave heating and healing properties of bitumen under microwave irradiation [15]. Patchai Murugan et al. studied the proper blending methods to enhance the bitumen properties using both conventional and microwave heating methods by using NFC as bitumen modifier and the blending of NFC with bitumen [16]. Jeffry et al. produced nanocarbon from coconut shell ash (NCA) as bitumen modifier [17]. Akbari et al. investigated the fatigue response of hot mix asphalt (HMA) containing nanoclay and nanoalumina modified bitumen and its relationship with surface free energy (SFE) parameters [18]. Hussein et al. found good dispersion of the NCP within the bitumen matrix by XRD pattern and Scanning Electron Microscopy (SEM) of the NCP-modified bitumen (NCPMB) [19]. Shi et al. analyzed the rheological properties of sixteen asphalts with different contents of nanosilica and Qingchuan rock asphalt by univariate analysis and variance analysis [20]. Ren et al. evaluated the influences of asphalt properties, temperature, and moisture damage on the Ad/Co of the asphalt, mastic, and mortar and investigated the relationships between the durability and indirect tensile strength (ITS) of the mixture and the $\mathrm{Ad} / \mathrm{Co}$ of binder by indirect tensile tests and Cantabro loss tests [21]. Jiang et al. proposed a novel method to characterize distribution of mortar film thickness in asphalt mixture through image processing techniques [22].

However, the existing research mainly focuses on the material analysis and formula development of nanomodified asphalt and has not been involved in the structural mechanics of nanomodified asphalt pavement [22-27]. In fact, because of the unique material characteristics of nanomodified asphalt, its mechanical role in pavement structure is bound to be quite different from that of traditional asphalt mixture [28-31]. It is necessary to carry out systematic mechanical analysis of pavement structure for nanomodified asphalt pavement and analyze the influence of material design parameters and pavement structure parameters on the mechanical response of nanomodified asphalt pavement. Thus, the pavement structure combination matching with nanomodified asphalt pavement is proposed, so as to prevent pavement diseases and material waste and improve the service quality of nanomodified asphalt pavement. Hence, considering that the semirigid base is the most widely used base type in China, two different structural models of nanomodified asphalt pavement are established according to the current specifications. The effects of pavement thickness, material type, and pavement design parameters on the mechanical response of nanomodified asphalt pavement are analyzed, and then the principle of optimal mechanical performance is taken and the optimal combination of nanomodified asphalt pavement structure is proposed.

\section{Calculation Model}

\subsection{Pavement Structure and Calculation Index Selection}

2.1.1. Selection of Loads and Calculation Points. "Specifications for Design of Highway Asphalt Pavement (JTG D50-2017)" in China stipulates that the pavement structure design adopts a double-circle uniformly distributed vertical load as the effective load for calculation. The load circle radius is $10.65 \mathrm{~cm}$, and the tire pressure is $0.707 \mathrm{MPa}$. The distribution of stress calculation points is shown in Figure 1. In the XOY horizontal plane of Figure 1, the coordinates of point $A$ are $(0,-15.975)$, the coordinates of point $B$ are $(0,-5.325)$, the coordinates of point $C$ are $(0$, $0)$, and the coordinates of point $D$ are $(0,-2.6625)$. Take the maximum value of point $A$, point $B$, point $C$, and point $D$ for mechanical response analysis. Direction $X$ is the driving direction.

2.1.2. Design Index and Mechanical Response Position. According to 6.2.1 of the "Specifications for Design of Highway Asphalt Pavement (JTG D50-2017)," the design index of pavements with different structures is shown in Table 1. At the same time, according to 6.2.2, the mechanical response and vertical position corresponding to each design index are shown in Table 2.

\subsection{Calculation of Nanomodified Asphalt Pavement Structure.} To scientifically analyze the calculation results and reduce the amount of testing, this project uses the orthogonal test method to calculate and analyze the nanomodified asphalt pavement structure.

According to the actual use of the arterial highways in China, two different working conditions are set: working condition I (surface layer of nanoasphalt mixture + bottom layer of SBS modified asphalt + semirigid base layer + semirigid subbase layer), and working condition II (surface layer of nanoasphalt mixture + bottom layer of SBS modified asphalt + semirigid base layer + the subbase layer of granules). By changing the thickness and modulus of different layers, the influences of pavement structure parameters on pavement mechanics response (see Table 1) are used to provide a basis for pavement structure design and propose the recommended pavement structure combination form based on the principle of optimal mechanical response. The orthogonal tests of wording conditions I and II are shown in Tables 3 and 4, respectively.

According to the Chinese standard "Specifications for Design of Highway Asphalt Pavement (JTG D50-2017)," the modulus of the $\mathrm{SiO}_{2}$-modified asphalt concrete with the nominal maximum particle size of $13.2 \mathrm{~mm}$ is $7310 \mathrm{MPa}$ and that with the nominal maximum particle size of $16 \mathrm{~mm}$ is $10,750 \mathrm{MPa}$. Hence, the modulus of the surfer layer is selected as $7310 \mathrm{MPa}, 9030 \mathrm{MPa}$ (average value), and 10,750 MPa.

\section{Data and Discussion}

The range histogram of working condition $\mathrm{I}$ is shown in Figure 2. According to the structural combination of the semirigid base and the semirigid subbase, two control indicators, namely, the bottom layer tensile stress of the inorganic binder stabilizing layer and the permanent deformation of the asphalt concrete layer, are selected.

Owing to the nano- $\mathrm{SiO}_{2}$ modified asphalt concrete, of which the modulus is tested via laboratory tests, being adopted in the surface layer, the modulus of the surface layer 

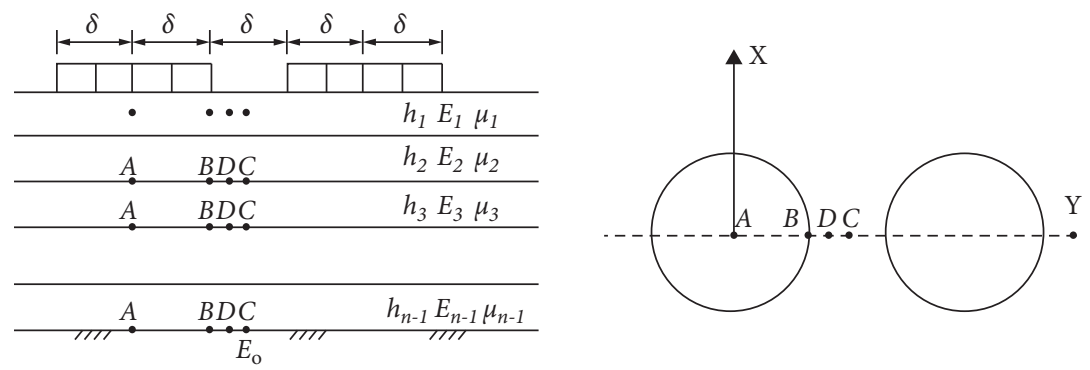

Figure 1: Compute point distribution.

Table 1: Design index of pavements with different structures.

\begin{tabular}{lcc}
\hline Base type & Subbase type & Design index \\
\hline $\begin{array}{l}\text { Inorganic binder } \\
\text { stabilizing type }\end{array}$ & $\begin{array}{c}\text { Inorganic binder } \\
\text { stabilizing type } \\
\text { Granule type }\end{array}$ & $\begin{array}{c}\text { Bottom layer tensile stress of inorganic binder stabilizing layer, permanent } \\
\text { deformation of asphalt concrete layer }\end{array}$ \\
\hline
\end{tabular}

TABLE 2: The mechanical response corresponding to each design index and its vertical position.

\begin{tabular}{lcc}
\hline Design index & Mechanical response & Vertical position \\
\hline $\begin{array}{l}\text { Bottom layer tensile stress of inorganic binder } \\
\text { stabilizing layer }\end{array}$ & $\begin{array}{c}\text { Horizontal tensile stress along the driving } \\
\text { direction }\end{array}$ & $\begin{array}{c}\text { The bottom of inorganic binder } \\
\text { stabilizing layer } \\
\text { Permanent deformation of asphalt concrete layer }\end{array}$ \\
\hline
\end{tabular}

TABLE 3: Working condition I the orthogonal test design.

\begin{tabular}{|c|c|c|c|c|c|c|c|c|c|}
\hline \multirow{2}{*}{ No. } & \multicolumn{2}{|c|}{ Surface layer } & \multicolumn{2}{|c|}{ Bottom layer } & \multicolumn{2}{|c|}{ Base layer } & \multicolumn{2}{|c|}{ Subbase layer } & \multirow{2}{*}{$\begin{array}{c}\text { Soil } \\
\text { foundation } \\
\text { Modulus } \\
(\mathrm{MPa})\end{array}$} \\
\hline & $\begin{array}{l}\text { Thickness } \\
(\mathrm{cm})\end{array}$ & $\begin{array}{l}\text { Modulus } \\
(\mathrm{MPa})\end{array}$ & $\begin{array}{l}\text { Thickness } \\
(\mathrm{cm})\end{array}$ & $\begin{array}{l}\text { Modulus } \\
(\mathrm{MPa})\end{array}$ & $\begin{array}{l}\text { Thickness } \\
(\mathrm{cm})\end{array}$ & $\begin{array}{l}\text { Modulus } \\
(\mathrm{MPa})\end{array}$ & $\begin{array}{l}\text { Thickness } \\
(\mathrm{cm})\end{array}$ & $\begin{array}{l}\text { Modulus } \\
\text { (MPa) }\end{array}$ & \\
\hline $1-1$ & 3 & 7310 & 5 & 19,264 & 30 & 9000 & 15 & 7000 & 50 \\
\hline $1-2$ & 3 & 9030 & 7 & 19,264 & 36 & 11,500 & 18 & 8500 & 50 \\
\hline $1-3$ & 3 & 10,750 & 9 & 19,264 & 40 & 14,000 & 20 & 10,000 & 50 \\
\hline $1-4$ & 4 & 7310 & 5 & 19,264 & 36 & 11,500 & 20 & 10,000 & 50 \\
\hline $1-5$ & 4 & 9030 & 7 & 19,264 & 40 & 14,000 & 15 & 7000 & 50 \\
\hline $1-6$ & 4 & 10,750 & 9 & 19,264 & 30 & 9000 & 18 & 8500 & 50 \\
\hline $1-7$ & 5 & 9030 & 5 & 19,264 & 30 & 14,000 & 18 & 10,000 & 50 \\
\hline $1-8$ & 5 & 10,750 & 7 & 19,264 & 36 & 9000 & 20 & 7000 & 50 \\
\hline $1-9$ & 5 & 7310 & 9 & 19,264 & 40 & 11,500 & 15 & 8500 & 50 \\
\hline $\begin{array}{l}1- \\
10\end{array}$ & 3 & 10,750 & 5 & 19,264 & 40 & 11,500 & 18 & 7000 & 50 \\
\hline $\begin{array}{l}1- \\
11\end{array}$ & 3 & 7310 & 7 & 19,264 & 30 & 14,000 & 20 & 8500 & 50 \\
\hline $\begin{array}{l}1- \\
12\end{array}$ & 3 & 9030 & 9 & 19,264 & 36 & 9000 & 15 & 10,000 & 50 \\
\hline $\begin{array}{l}1- \\
13\end{array}$ & 4 & 9030 & 5 & 19,264 & 40 & 9000 & 20 & 8500 & 50 \\
\hline $\begin{array}{l}1- \\
14\end{array}$ & 4 & 10,750 & 7 & 19,264 & 30 & 11,500 & 15 & 10,000 & 50 \\
\hline $\begin{array}{l}1- \\
15\end{array}$ & 4 & 7310 & 9 & 19,264 & 36 & 14,000 & 18 & 7000 & 50 \\
\hline $\begin{array}{l}1- \\
16\end{array}$ & 5 & 10,750 & 5 & 19,264 & 36 & 14,000 & 15 & 8500 & 50 \\
\hline $\begin{array}{l}1- \\
17\end{array}$ & 5 & 7310 & 7 & 19,264 & 40 & 9000 & 18 & 10,000 & 50 \\
\hline $\begin{array}{l}1- \\
18\end{array}$ & 5 & 9030 & 9 & 19,264 & 30 & 11,500 & 20 & 7000 & 50 \\
\hline
\end{tabular}


TABLE 4: Working condition II the orthogonal test design.

\begin{tabular}{|c|c|c|c|c|c|c|c|c|c|}
\hline \multirow[b]{2}{*}{ No. } & \multicolumn{2}{|c|}{ Surface layer } & \multicolumn{2}{|c|}{ Bottom layer } & \multicolumn{2}{|c|}{ Base layer } & \multicolumn{2}{|c|}{ Subbase layer } & \multirow{2}{*}{$\begin{array}{c}\text { Soil } \\
\text { foundation } \\
\text { Modulus } \\
(\mathrm{MPa})\end{array}$} \\
\hline & $\begin{array}{l}\text { Thickness } \\
(\mathrm{cm})\end{array}$ & $\begin{array}{l}\text { Modulus } \\
(\mathrm{MPa})\end{array}$ & $\begin{array}{c}\text { Thickness } \\
(\mathrm{cm})\end{array}$ & $\begin{array}{l}\text { Modulus } \\
(\mathrm{MPa})\end{array}$ & $\begin{array}{l}\text { Thickness } \\
(\mathrm{cm})\end{array}$ & $\begin{array}{l}\text { Modulus } \\
(\mathrm{MPa})\end{array}$ & $\begin{array}{l}\text { Thickness } \\
(\mathrm{cm})\end{array}$ & $\begin{array}{l}\text { Modulus } \\
(\mathrm{MPa})\end{array}$ & \\
\hline $2-1$ & 3 & 7310 & 5 & 19,264 & 30 & 9000 & 15 & 200 & 50 \\
\hline $2-2$ & 3 & 9030 & 7 & 19,264 & 36 & 11,500 & 18 & 320 & 50 \\
\hline $2-3$ & 3 & 10,750 & 9 & 19,264 & 40 & 14,000 & 20 & 440 & 50 \\
\hline $2-4$ & 4 & 7310 & 5 & 19,264 & 36 & 11,500 & 20 & 440 & 50 \\
\hline $2-5$ & 4 & 9030 & 7 & 19,264 & 40 & 14,000 & 15 & 200 & 50 \\
\hline $2-6$ & 4 & 10,750 & 9 & 19,264 & 30 & 9000 & 18 & 320 & 50 \\
\hline $2-7$ & 5 & 9030 & 5 & 19,264 & 30 & 14,000 & 18 & 440 & 50 \\
\hline $2-8$ & 5 & 10,750 & 7 & 19,264 & 36 & 9000 & 20 & 200 & 50 \\
\hline $2-9$ & 5 & 7310 & 9 & 19,264 & 40 & 11,500 & 15 & 320 & 50 \\
\hline $\begin{array}{l}2- \\
10\end{array}$ & 3 & 10,750 & 5 & 19,264 & 40 & 11,500 & 18 & 200 & 50 \\
\hline $\begin{array}{l}2- \\
11\end{array}$ & 3 & 7310 & 7 & 19,264 & 30 & 14,000 & 20 & 320 & 50 \\
\hline $\begin{array}{l}2- \\
12\end{array}$ & 3 & 9030 & 9 & 19,264 & 36 & 9000 & 15 & 440 & 50 \\
\hline $\begin{array}{l}2- \\
13\end{array}$ & 4 & 9030 & 5 & 19,264 & 40 & 9000 & 20 & 320 & 50 \\
\hline $\begin{array}{l}2- \\
14\end{array}$ & 4 & 10,750 & 7 & 19,264 & 30 & 11,500 & 15 & 440 & 50 \\
\hline $\begin{array}{l}2- \\
15\end{array}$ & 4 & 7310 & 9 & 19,264 & 36 & 14,000 & 18 & 200 & 50 \\
\hline $\begin{array}{l}2- \\
16\end{array}$ & 5 & 10,750 & 5 & 19,264 & 36 & 14,000 & 15 & 320 & 50 \\
\hline $\begin{array}{l}2- \\
17\end{array}$ & 5 & 7310 & 7 & 19,264 & 40 & 9000 & 18 & 440 & 50 \\
\hline $\begin{array}{l}2- \\
18\end{array}$ & 5 & 9030 & 9 & 19,264 & 30 & 11,500 & 20 & 200 & 50 \\
\hline
\end{tabular}

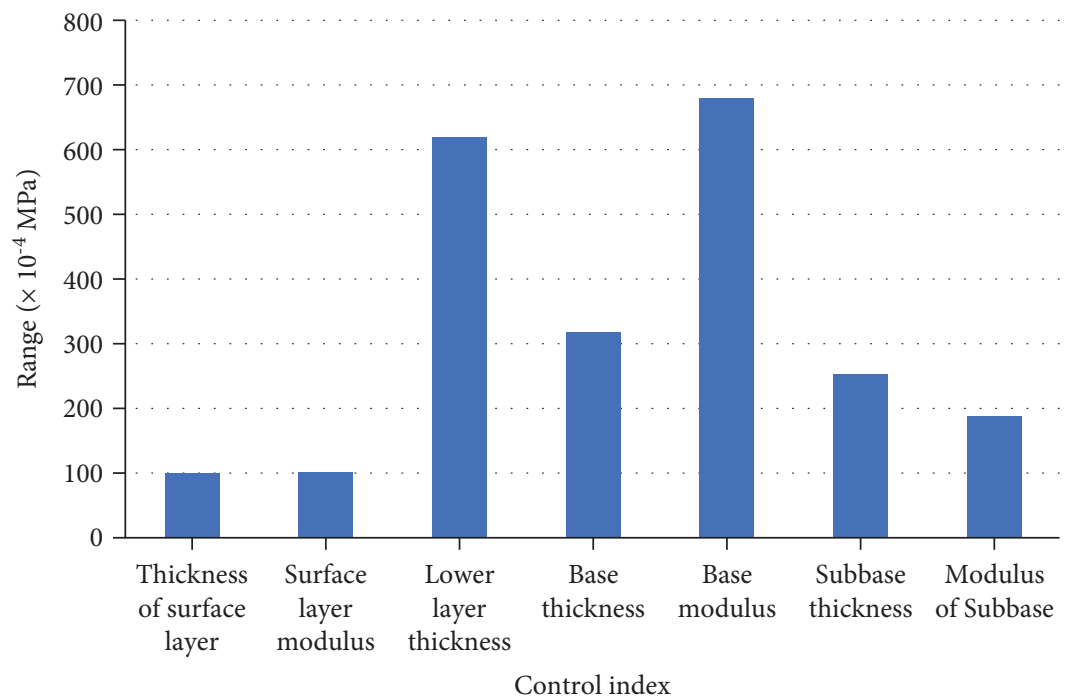

(a)

Figure 2: Continued. 


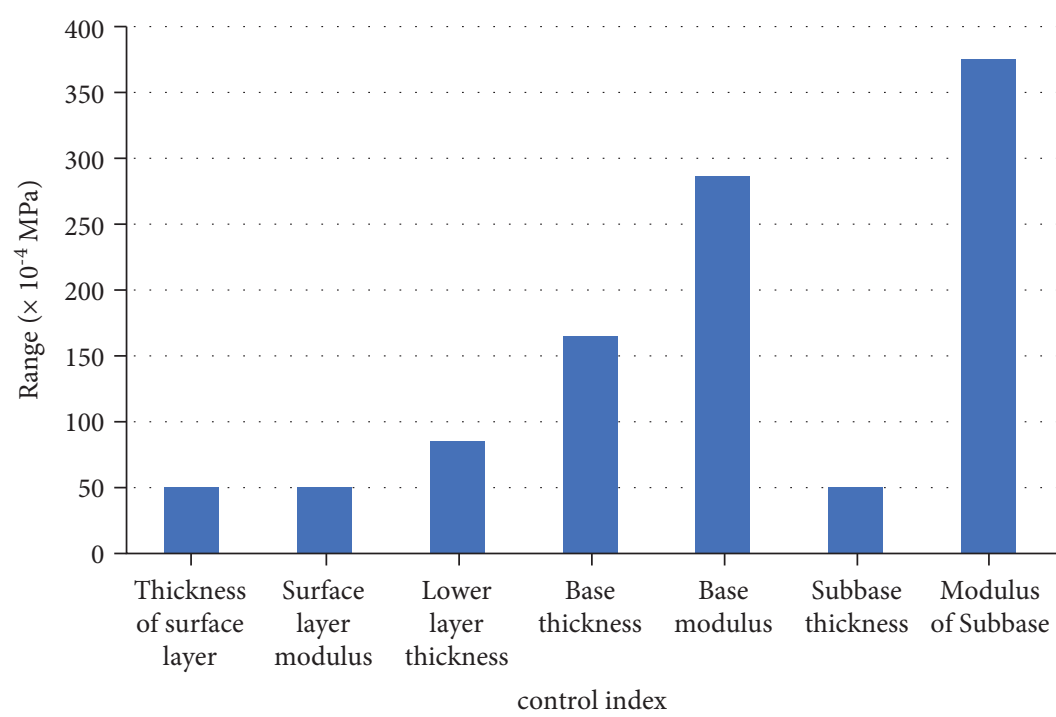

(b)

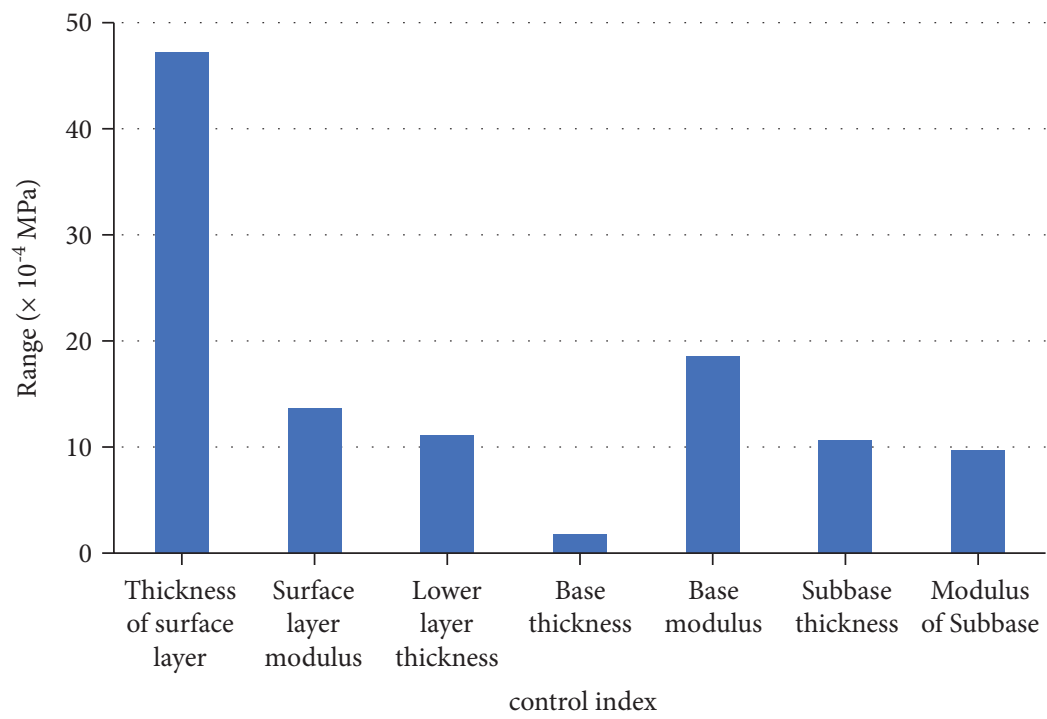

(c)

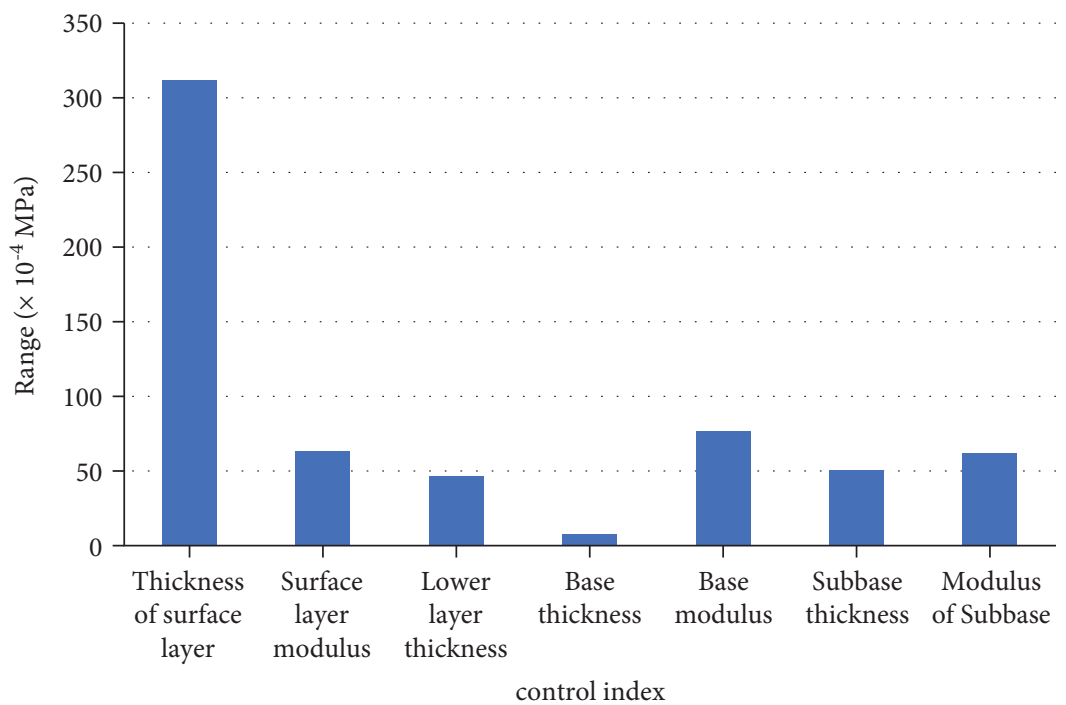

(d)

Figure 2: Range diagram of working condition I. (a) Tensile stress at the bottom of inorganic binder base course. (b) Tensile stress of inorganic binder subbase. (c) Permanent deformation of asphalt concrete surface layer. (d) Permanent deformation of the lower layer of asphalt concrete layer. 
is not considered in this study. The modulus of other layers is selected in accordance with the Chinese standard "Specifications for Design of Highway Asphalt Pavement."

As shown in Figure 2(a), the thickness of the lower layer and the modulus of the base layer have a significant effect on the bottom layer tensile stress of the inorganic binder stabilizing layer, followed by the thickness of the base layer. As shown in Figure 2(b), the modulus of the base layer and the modulus of the subbase layer have a greater influence on the bottom layer tensile stress of the inorganic binder stabilizing subbase layer, followed by the thickness of the base layer. As shown in Figure 2(c), the thickness of the surface layer has a significant effect on the permanent deformation of the asphalt concrete surface layer. As shown in Figure 2(d), the thickness of the surface layer has a significant effect on the permanent deformation of the underlying layer of asphalt concrete.

Figure 3(a) shows that, with the increase of the thickness of the underlying layer, the thickness of the base layer, and the modulus of the base layer, the bottom layer tensile stress of the inorganic binder stabilizing base layer decreases. The increase in the thickness of the underlying layer from $5 \mathrm{~cm}$ to $7 \mathrm{~cm}$ has a more significant effect on the bottom layer tensile stress of the inorganic binder stabilizing base layer than the increase in the thickness of the underlying layer from $7 \mathrm{~cm}$ to $9 \mathrm{~cm}$. When the thickness of the base layer increases from $30 \mathrm{~cm}$ to $36 \mathrm{~cm}$, the bottom layer tensile stress of the inorganic binder stabilizing base layer decreases slowly, and when the thickness of the base layer increases from $36 \mathrm{~cm}$ to $40 \mathrm{~cm}$, the bottom layer tensile stress of the inorganic binder stabilizing base layer decreases relatively quickly. The modulus of the base layer has a more uniform effect on the bottom layer tensile stress of the inorganic binder stabilizing the base layer. As shown in Figure 3(b), as the modulus of the base layer increases, the bottom layer tensile stress of the inorganic binder stabilizing subbase layer first decreases and then increases. As the modulus of the base layer and the thickness of the base layer increase, the bottom layer tensile stress of the inorganic binder stabilizing subbase layer decreases accordingly. When the modulus of the base layer increases from 9000 to $11,500 \mathrm{MPa}$, the decrease in the bottom layer tensile stress of the inorganic binder stabilizing base layer is smaller than the increase in the bottom layer tensile stress of the inorganic binder stabilizing subbase layer when the modulus of the base layer increases from 9000 to $14,000 \mathrm{MPa}$. The modulus of the subbase layer increased from $7000 \mathrm{MPa}$ to $8500 \mathrm{MPa}$, and the bottom layer tensile stress of the stabilizing subbase layer changed slowly. The thickness of the base layer has a more uniform effect on the bottom layer tensile stress of the inorganic binder stabilizing subbase layer. Figure 3(c) shows that, as the thickness of the surface layer increases, the permanent deformation of the surface layer of the asphalt concrete layer first decreases and then increases. Figure 3(d) shows that, as the thickness of the surface layer increases, the permanent deformation of the underlying layer of the asphalt concrete layer decreases uniformly.

In conclusion, combined with economic efficiency, the recommended pavement structure is as follows: surface layer thickness $4 \mathrm{~cm}+$ underlying layer thickness $7 \mathrm{~cm}+$ base layer thickness $36 \mathrm{~cm}+$ subbase layer thickness $15 \mathrm{~cm}$. For the modulus of the base layer, the value should be medium to high, and for the modulus of the subbase layer, the value should be as high as possible, and for the modulus of the surface layer, the value should be as high as possible. The modulus of the surface layer can be flexibly selected according to the actual situation of the project. The range diagram of condition 2 is shown in Figure 4.

As shown in Figure 4(a), the thickness of the base course has the greatest influence on the bottom tensile stress of the inorganic binder layer, the thickness of the lower layer and the modulus of the base course also have a significant influence on the bottom tensile stress of inorganic binder layer, and the other four control indexes have little influence on the bottom tensile stress of inorganic binder layer. As shown in Figure 4(b), there is little difference in the influence level of the three control indexes on the permanent deformation of the surface layer of the asphalt mixture layer. As shown in Figure 4(c), among the seven control indexes, the influence of surface layer thickness, lower layer thickness, and base modulus on the permanent deformation of the lower layer of asphalt mixture is more obvious.

It can be seen from Figure 5(a) that, with the increase of the thickness of the base course and the thickness of the lower layer, the tensile stress at the bottom of the inorganic binder stable layer decreases, but the influence of the thickness of the base course on the decreasing trend of the tensile stress at the bottom of the inorganic binder stable layer is more uniform, while the influence of the thickness of the lower layer on the decreasing trend of the tensile stress at the bottom of the inorganic binder stable layer is not uniform, when the thickness of the lower layer increases from $5 \mathrm{~cm}$ to $7 \mathrm{~cm}$, the reduction rate of the tensile stress at the bottom of the stabilized layer of the inorganic binder is 1.843 times that when the thickness of the lower layer increases from $7 \mathrm{~cm}$ to $9 \mathrm{~cm}$. The effect of increasing the thickness of the lower layer on the tensile stress at the bottom of the stabilized layer of the inorganic binder is higher than that when the thickness of the lower layer is $7-9 \mathrm{~cm}$. With the increase of the base modulus, the tensile stress at the bottom of the inorganic binder stable layer increases and the influence of the base modulus on the decreasing trend of the tensile stress at the bottom of the inorganic binder stable layer is uniform. It can be seen from Figure 5(b) that, with the increase of surface layer thickness, surface layer modulus, and subbase modulus, the permanent deformation of asphalt mixture surface layer first decreases and then increases, while with the increase of lower layer thickness, base layer thickness, base layer modulus, and subbase thickness, it first increases and then decreases. Among them, the influence trend of the increase of the thickness of the lower layer and the modulus of the base layer on the permanent deformation of the surface layer of the asphalt mixture layer is more similar, both of which are in the first half of the influence degree which is greater, and the latter half has little influence. The influence trend of the increase of the 


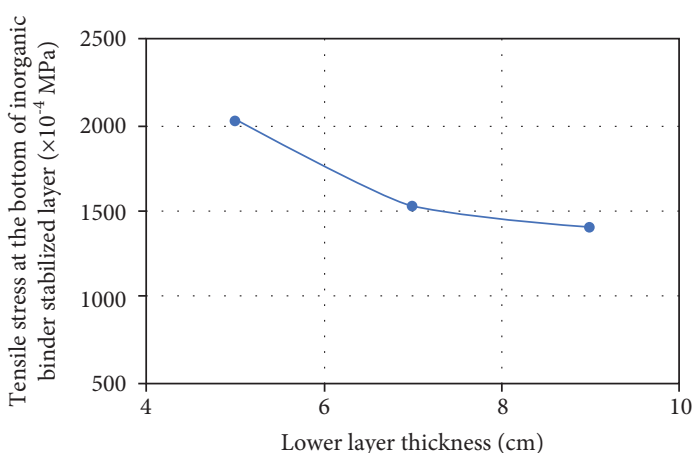

$\left(a_{1}\right)$

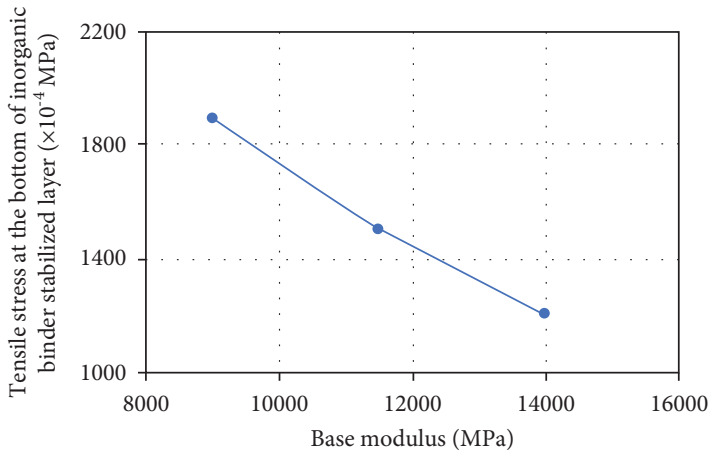

$\left(a_{3}\right)$

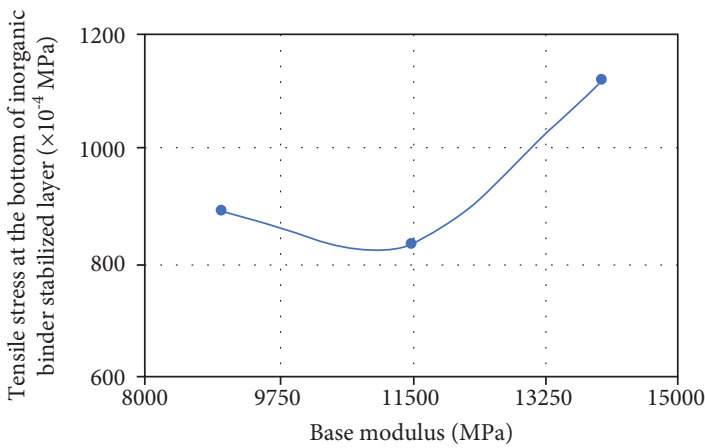

$\left(b_{2}\right)$

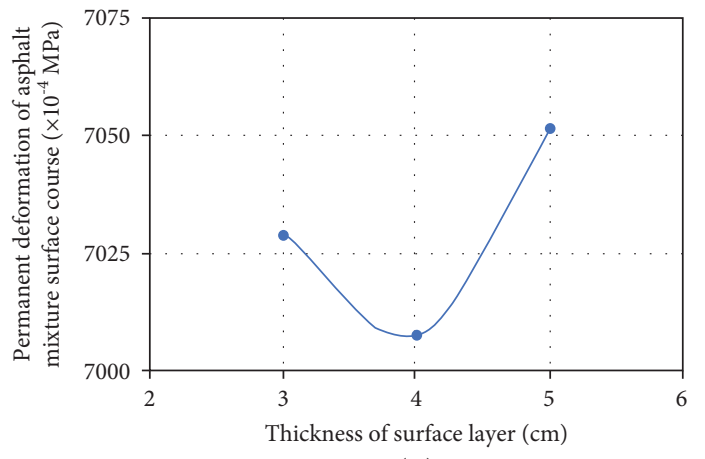

$\left(c_{1}\right)$

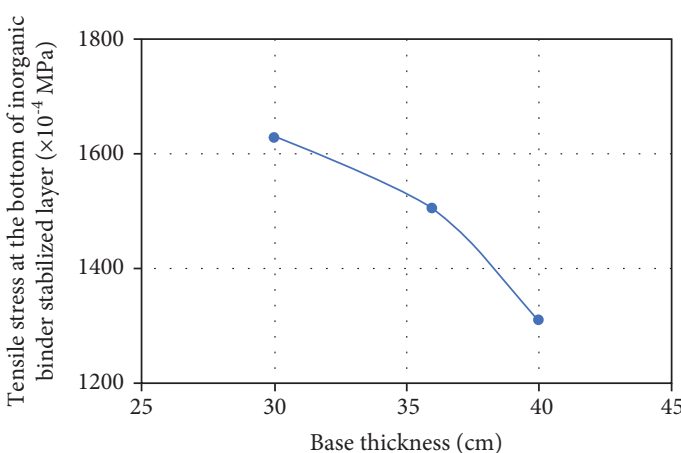

$\left(a_{2}\right)$

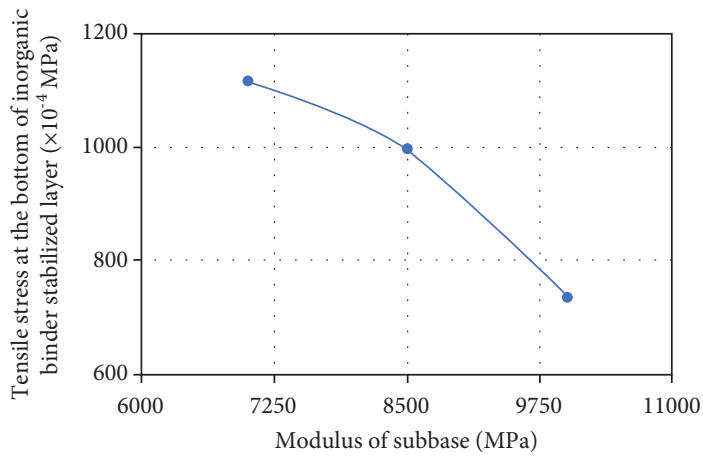

$\left(b_{1}\right)$

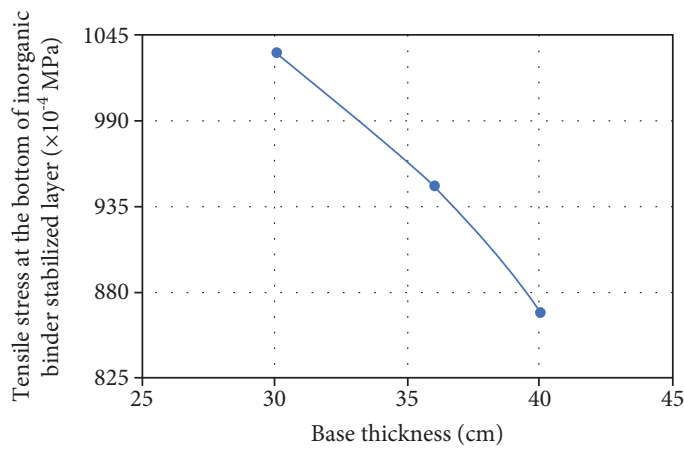

$\left(b_{3}\right)$

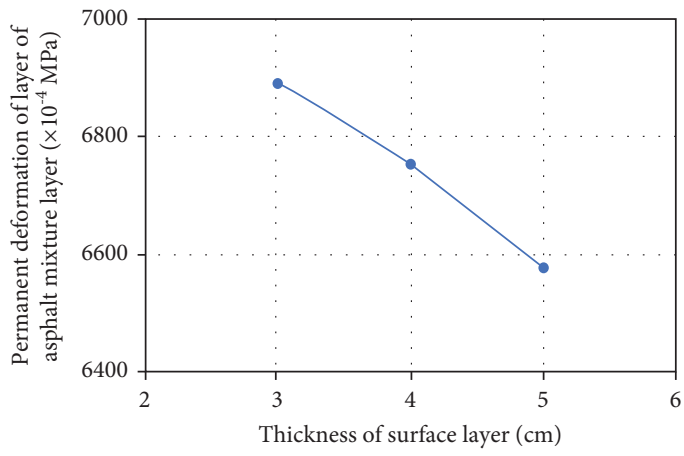

$\left(d_{1}\right)$

Figure 3: Trend chart of working condition I.

thickness of the base layer and subbase layer on the permanent deformation of the surface layer of the asphalt mixture layer is more similar, both of which are in the first half of the influence degree which has little influence, and the latter half is greater. It can be seen from Figure 5(c) that, with the increase of the surface layer thickness in the pavement structure, the permanent deformation of the surface layer of the asphalt mixture layer gradually decreases, and, when the surface layer thickness increases from $3 \mathrm{~m}$ to $4 \mathrm{~m}$, the reduction rate of permanent deformation of asphalt mixture surface layer is 130.29 times that when the surface layer thickness increases from $4 \mathrm{~cm}$ 


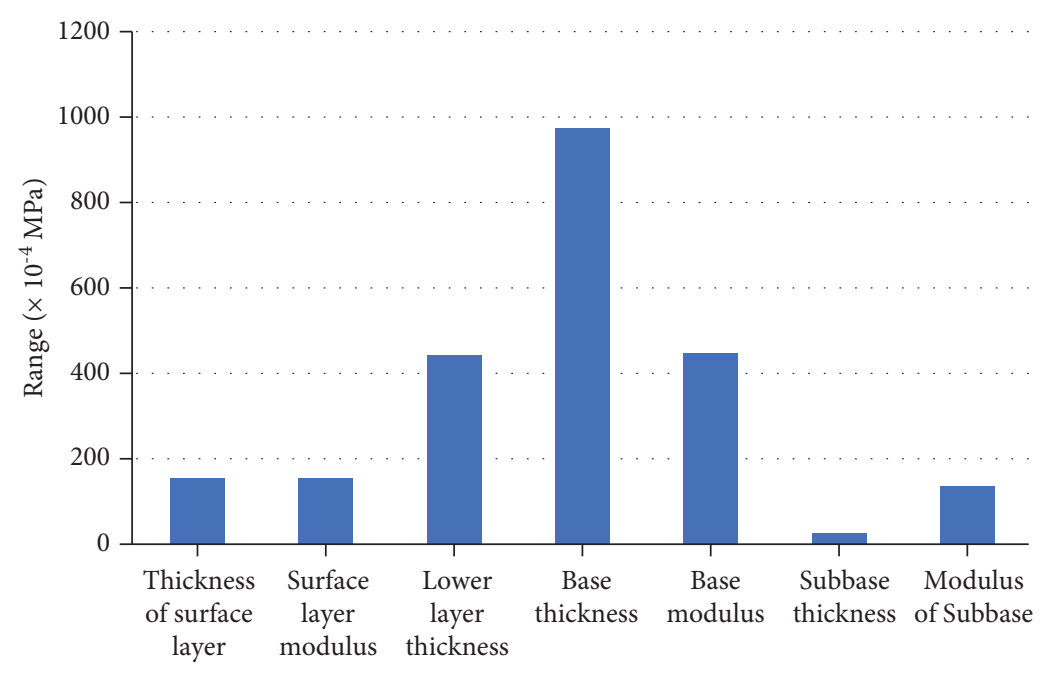

control index

(a)

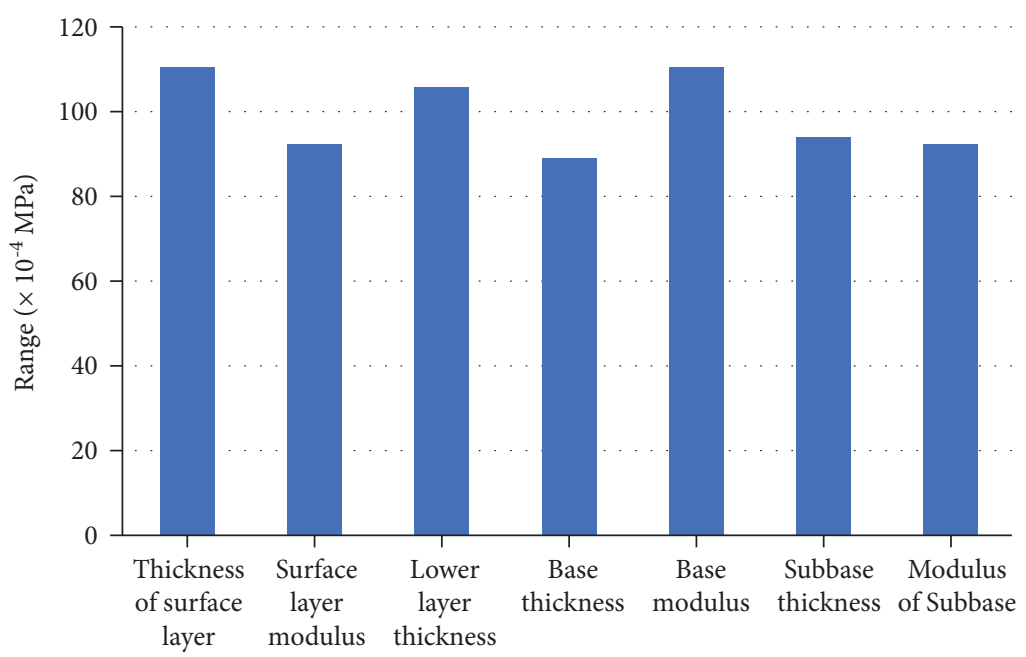

control index

(b)

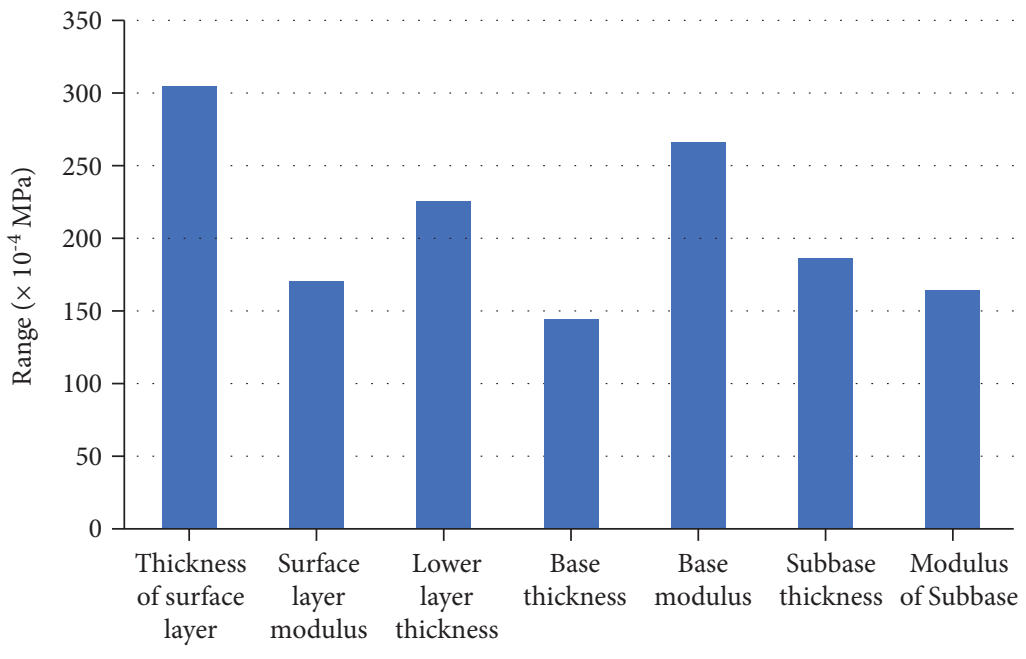

control index

(c)

Figure 4: Range diagram of working condition II. (a) Bottom layer tensile stress of inorganic binder stabilizing layer. (b) Permanent deformation of asphalt concrete surface layer. (c) Permanent deformation of the lower layer of asphalt concrete layer. 


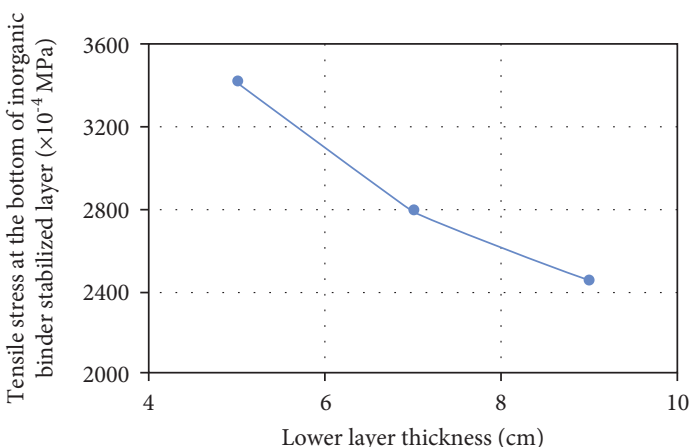

(a1)

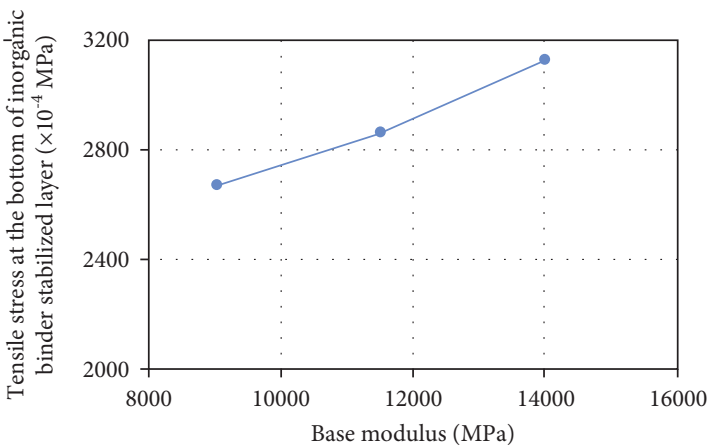

(a3)

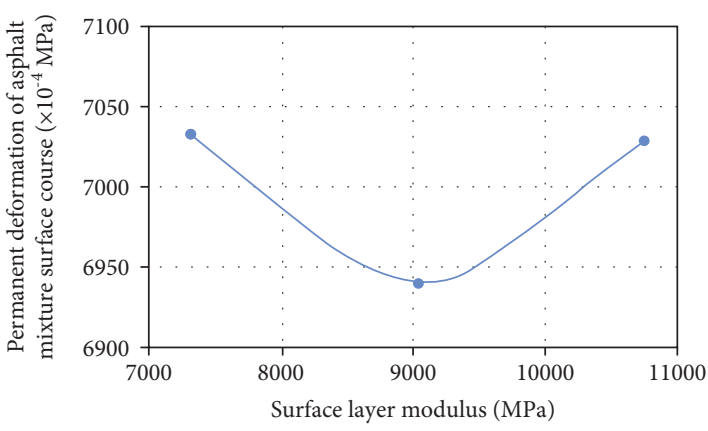

(b2)

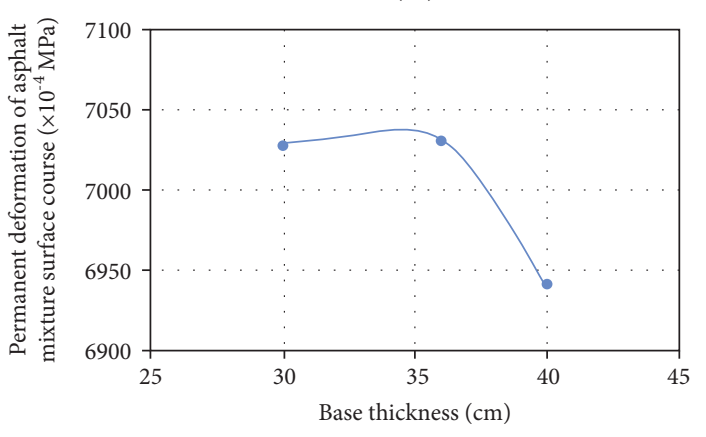

(b4)

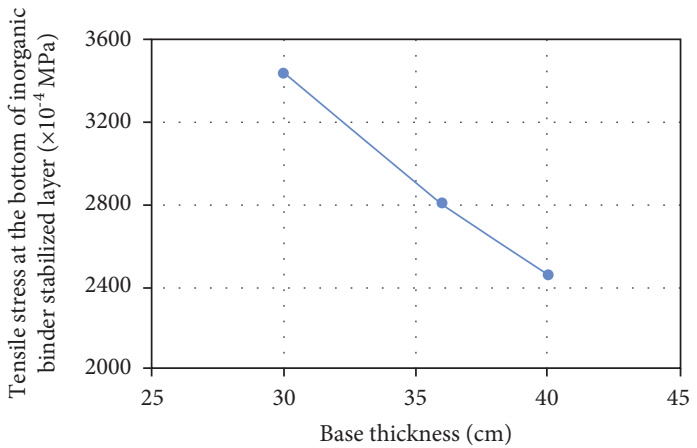

(a2)

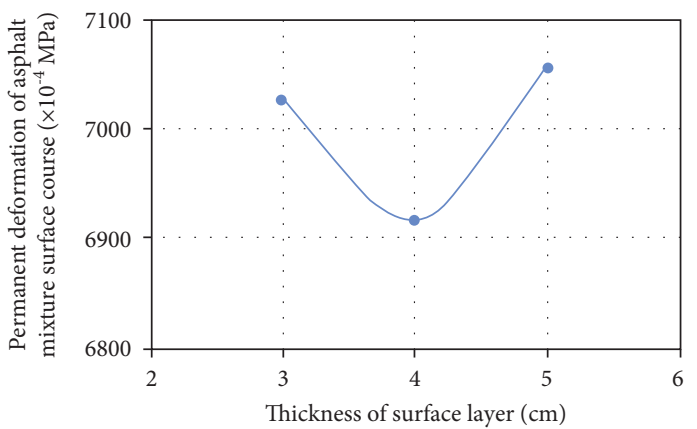

(b1)

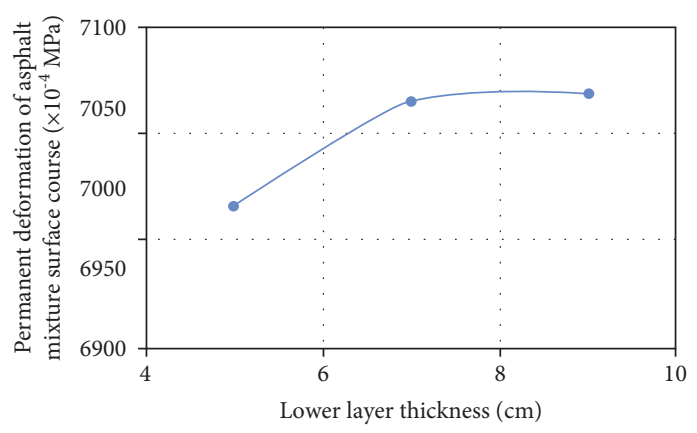

(b3)

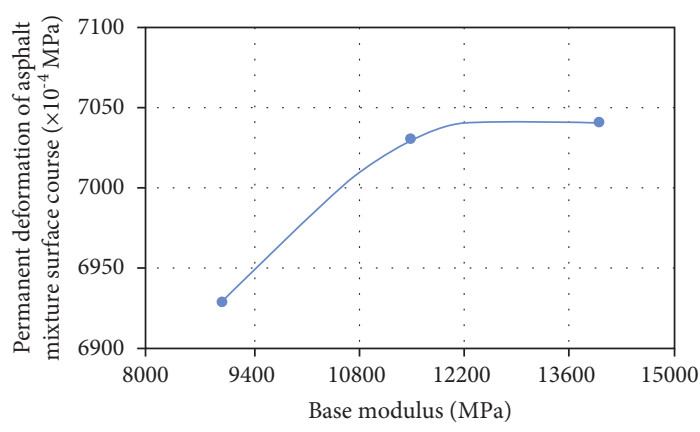

(b5)

(a)

Figure 5: Continued. 


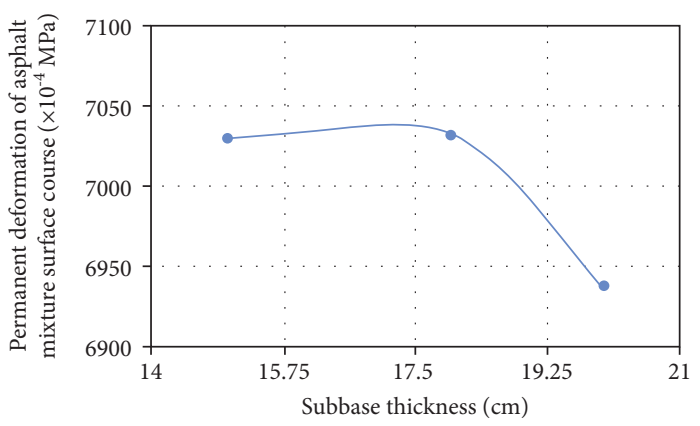

(b6)

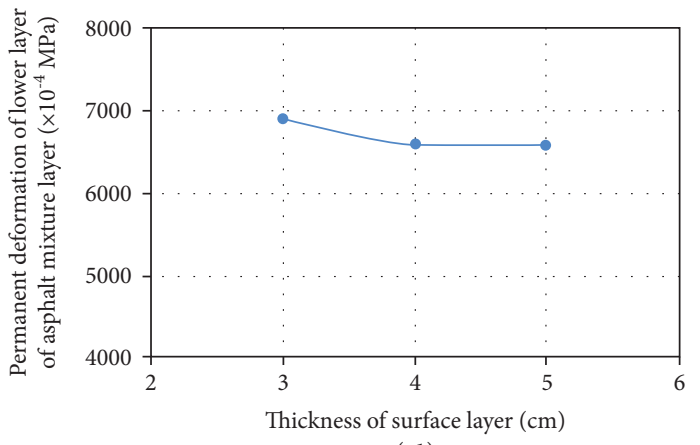

(c1)

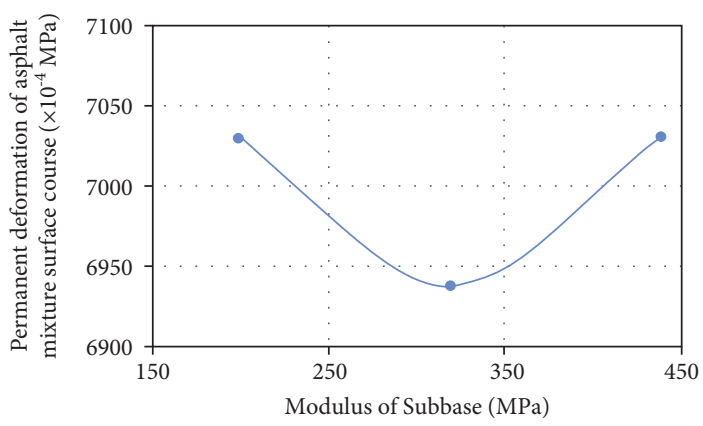

(b7)

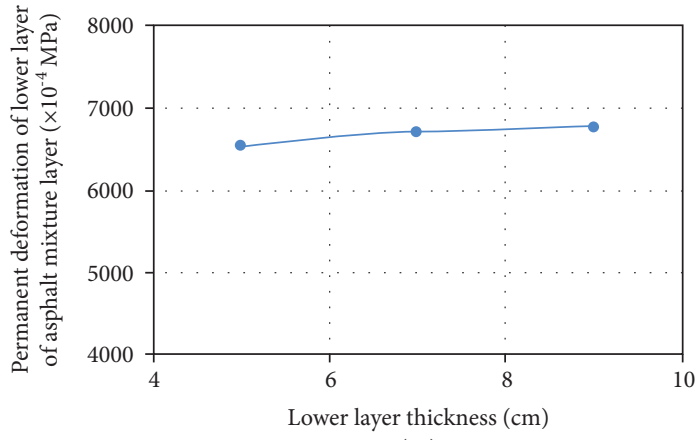

(c2)

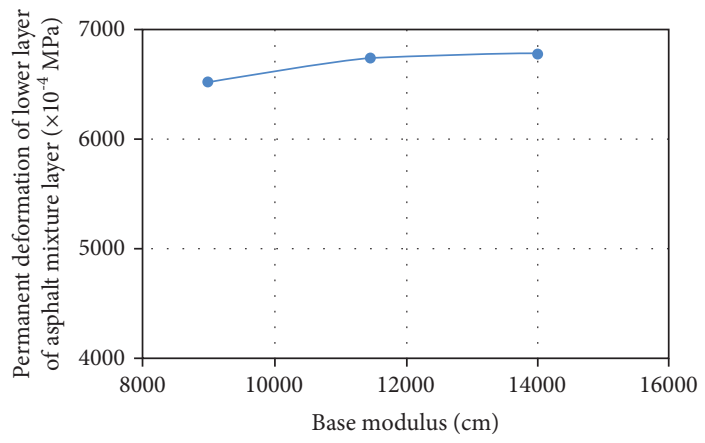

(c3)

(b)

FIgURE 5: Trend chart of working condition II.

to $5 \mathrm{~cm}$ (the permanent deformation of asphalt mixture surface layer basically does not change when the surface layer thickness increases from $4 \mathrm{~cm}$ to $5 \mathrm{~cm}$ ). The permanent deformation of the surface layer of the asphalt mixture layer increases gradually, and it increases rapidly in the first half and hardly changes in the second half. When the thickness of the lower layer increases from $5 \mathrm{~m}$ to $7 \mathrm{~m}$, the increase rate of permanent deformation of the asphalt mixture surface layer is 3.35 times that of the surface layer from $7 \mathrm{~cm}$ to $9 \mathrm{~cm}$. When the base modulus increases from $9000 \mathrm{MPa}$ to $11,500 \mathrm{MPa}$, the increase rate of permanent deformation of the asphalt mixture surface layer is 5.77 times that when the base modulus increases from $11,500 \mathrm{MPa}$ to $14,000 \mathrm{MPa}$. In conclusion, combined with economy, the recommended pavement structure is as follows: the thickness of the surface layer is $4 \mathrm{~cm}+$ the thickness of the lower layer is $5 \mathrm{~cm}+$ the thickness of the base layer is $40 \mathrm{~cm}$ + the thickness of the subbase layer is $20 \mathrm{~cm}$, the modulus of the base layer should be low, and the modulus of subbase layer and surface layer can be flexibly selected according to the actual situation of the project.

After analyzing Figures 2 to 4, we see that, under different working conditions, the degree of influence of the seven control indicators on the corresponding design index is shown in Table 5 .

After integrating the mechanical response analysis results and economic aspects, the recommended pavement structure under the two working conditions is shown in Table 6. 
TABLE 5: The influence degree of control indicators.

\begin{tabular}{|c|c|c|c|c|c|c|c|c|c|}
\hline $\begin{array}{l}\text { Working } \\
\text { condition }\end{array}$ & Design index & & $\begin{array}{l}\text { Thickness of } \\
\text { surface layer }\end{array}$ & $\begin{array}{l}\text { Surface } \\
\text { layer } \\
\text { modulus }\end{array}$ & $\begin{array}{c}\text { Lower } \\
\text { layer } \\
\text { thickness }\end{array}$ & $\begin{array}{c}\text { Base } \\
\text { thickness }\end{array}$ & $\begin{array}{c}\text { Base } \\
\text { modulus }\end{array}$ & $\begin{array}{l}\text { Subbase } \\
\text { thickness }\end{array}$ & $\begin{array}{l}\text { Modulus of } \\
\text { subbase }\end{array}$ \\
\hline \multirow{4}{*}{$\begin{array}{l}\text { Working } \\
\text { condition I }\end{array}$} & \multirow{4}{*}{$\begin{array}{c}\text { Tensile stress at the } \\
\text { bottom of inorganic } \\
\text { binder stabilized layer } \\
\text { Permanent } \\
\text { deformation of } \\
\text { asphalt mixture layer }\end{array}$} & $\begin{array}{c}\text { The basic } \\
\text { level }\end{array}$ & & & $\checkmark$ & & $\checkmark$ & & \\
\hline & & Subbase & & & & & $\checkmark$ & & $\checkmark \checkmark$ \\
\hline & & & $\checkmark$ & & & & & & \\
\hline & & $\begin{array}{l}\text { Lower } \\
\text { layer }\end{array}$ & $\checkmark$ & & & & & & \\
\hline \multirow{3}{*}{$\begin{array}{l}\text { Working } \\
\text { condition II }\end{array}$} & $\begin{array}{l}\text { Tensile stress at the } \\
\text { bottom of inorganic } \\
\text { binder stabilized layer }\end{array}$ & - & & \multirow{3}{*}{$\checkmark$} & $\checkmark$ & $\checkmark \checkmark$ & $\checkmark$ & \multirow{3}{*}{$\checkmark$} & \multirow{3}{*}{$\checkmark$} \\
\hline & \multirow{2}{*}{$\begin{array}{c}\text { Permanent } \\
\text { deformation of } \\
\text { asphalt concrete layer }\end{array}$} & $\begin{array}{l}\text { Surface } \\
\text { layer }\end{array}$ & $\checkmark$ & & $\checkmark$ & $\checkmark$ & $\checkmark$ & & \\
\hline & & $\begin{array}{l}\text { Lower } \\
\text { layer }\end{array}$ & $\checkmark$ & & $\checkmark$ & & $\checkmark$ & & \\
\hline
\end{tabular}

TABle 6: Recommended pavement structure.

\begin{tabular}{|c|c|c|c|c|c|c|c|}
\hline $\begin{array}{l}\text { Working } \\
\text { condition }\end{array}$ & $\begin{array}{c}\text { Thickness of } \\
\text { surface layer }(\mathrm{cm})\end{array}$ & $\begin{array}{l}\text { Surface layer } \\
\text { modulus (MPa) }\end{array}$ & $\begin{array}{l}\text { Lower layer } \\
\text { thickness }(\mathrm{cm})\end{array}$ & $\begin{array}{c}\text { Base } \\
\text { thickness } \\
(\mathrm{cm})\end{array}$ & $\begin{array}{l}\text { Base modulus } \\
(\mathrm{MPa})\end{array}$ & $\begin{array}{c}\text { Subbase } \\
\text { thickness }(\mathrm{cm})\end{array}$ & $\begin{array}{c}\text { Modulus of } \\
\text { subbase (MPa) }\end{array}$ \\
\hline $\begin{array}{l}\text { Working } \\
\text { condition I }\end{array}$ & 4 & Flexible & 7 & 36 & $\begin{array}{l}\text { Medium high } \\
\text { value }\end{array}$ & 15 & High value \\
\hline $\begin{array}{l}\text { Working } \\
\text { condition II }\end{array}$ & 4 & Flexible & 5 & 40 & Low value & 20 & Flexible \\
\hline
\end{tabular}

\section{Conclusions}

By changing different layer thickness and modulus, we can study the influence of the nanomodified asphalt pavement structure on pavement mechanics response and then propose the recommended pavement structure combination form of the nanomodified asphalt.

The bottom layer tensile stress of the inorganic binder stabilizing subbase layer is greatly affected by the thickness of the underlying layer and the modulus of the base layer, followed by the thickness of the base layer. The bottom layer tensile stress of the inorganic binder stabilizing subbase layer is more greatly affected by the modulus of the base layer and the modulus of the subbase layer, followed by the thickness of the base layer. The thickness of the surface layer has a significant effect on the permanent deformation of the asphalt concrete surface layer, and with the increase of the thickness, the permanent deformation first decreases and then increases. The thickness of the surface layer has a significant effect on the permanent deformation of the underlying layer of asphalt concrete, and as the thickness of the surface layer increases, the permanent deformation decreases uniformly.

Considering the economic aspect, the recommended pavement structure for working condition I is as follows: the thickness of the surface layer $4 \mathrm{~cm}+$ the thickness of the underlying layer $7 \mathrm{~cm}$ + the thickness of the base layer $36 \mathrm{~cm}+$ the thickness of the subbase layer $15 \mathrm{~cm}$. For the modulus of the base layer, the value should be medium to high, for the modulus of the subbase layer, the value should be as high as possible, and the modulus of the surface layer can be flexibly selected according to the actual situation of the project. The recommended pavement structure for working condition II is as follows: the thickness of the surface layer $4 \mathrm{~cm}+$ the thickness of the underlying layer $5 \mathrm{~cm}$ the thickness of the base layer $40 \mathrm{~cm}$ + the thickness of the subbase layer $20 \mathrm{~cm}$. For the modulus of the base layer, the value should be low, and for the modulus of the subbase layer and surface layer, it can be flexibly selected according to the actual situation of the project.

\section{Data Availability}

The data used to support the findings of this study are included within the article.

\section{Conflicts of Interest}

The authors declare that they have no conflicts of interest.

\section{Acknowledgments}

This study was sponsored in part by the Highway Construction Science and Technology Projects of Shandong HiSpeed Co., Ltd. (Grant no. QLTD-2019-A-FW-0036), to which the authors are very grateful. 


\section{References}

[1] J. Ren, B. Xue, and L. Zhang, "Characterization and prediction of rutting resistance of rock asphalt mixture under the coupling effect of water and high-temperature," Construction and Building Materials, vol. 254, Article ID 119316, 2020.

[2] Y. Jiang, Y. Yi, J. Fan, T. Tian, and C. Deng, "Laboratory investigation on the heat dissipation regularity and road performance of different pavement structure combinations by double-layer paving," Construction and Building Materials, vol. 284, Article ID 122785, 2021.

[3] C. Deng, Y. Jiang, K. Yuan, T. Tian, and Y. Yi, "Mechanical properties of vertical vibration compacted lime-fly ash-stabilized macadam material," Construction and Building Materials, vol. 251, Article ID 119089, 2020.

[4] Y. Jiang, K. Yuan, C. Deng, and T. Tian, "Fatigue performance of cement-stabilized crushed gravel produced using vertical vibration compaction method," Journal of Materials in Civil Engineering, vol. 32, no. 11, Article ID 04020318, 2020.

[5] J. Ren, D. Li, and S. Wang, "Combined effect of compaction methods and loading conditions on the deformation behaviour of unbound granular material," Advances in Civil Engineering, vol. 2020, Article ID 2419102, 16 pages, 2020.

[6] P. Caputo, M. Porto, R. Angelico, V. Loise, P. Calandra, and C. O. Rossi, "Bitumen and asphalt concrete modified by nanometer-sized particles: basic concepts, the state of the art and future perspectives of the nanoscale approach-science direct," Advances in Colloid and Interface Science, vol. 285, no. 275, Article ID 102283, 2020.

[7] R. Li, F. Xiao, S. Amirkhanian, Z. You, and J. Huang, "Developments of nano materials and technologies on asphalt materials - a review," Construction and Building Materials, vol. 143, pp. 633-648, 2017.

[8] L. Sun, X. Xin, and J. Ren, "Asphalt modification using nanomaterials and polymers composite considering high and low temperature performance," Construction and Building Materials, vol. 133, pp. 358-366, 2017.

[9] Y. Ma, L. Li, H. Wang, W. Wang, and K. Zheng, "Laboratory study on performance evaluation and automobile exhaust degradation of nano-tio2 particles-modified asphalt materials," Advances in Materials Science and Engineering, vol. 2021, no. 9, 13 pages, Article ID 5574013, 2021.

[10] J. Hu and X. Yu, "Performance evaluation of solar-responsive asphalt mixture with thermochromic materials and nano-tio2 scatterers," Construction and Building Materials, vol. 247, Article ID 118605, 2020.

[11] C. Hu, J. Ma, H. Jiang, Z. Chen, and J. Zhao, "Evaluation of nano- $\mathrm{TiO}_{2}$ modified waterborne epoxy resin as fog seal and exhaust degradation material in asphalt pavement," Journal of Testing and Evaluation, vol. 45, no. 1, Article ID 20160157, 2017.

[12] R. Li, J. Pei, and C. Sun, "Effect of nano-zno with modified surface on properties of bitumen," Construction and Building Materials, vol. 98, no. 15, pp. 656-661, 2015.

[13] S. Karahancer, "Effect of aluminum oxide nano particle on modified bitumen and hot mix asphalt," Petroleum Science and Technology, vol. 2020, Article ID 1783292, 12 pages, 2020.

[14] A. Sarkar and F. Hojjati, "The effect of nano-silica material and alkali resistant glass fiber on the OGFC asphalt mixture," International Journal of Pavement Engineering, vol. 22, no. 29, pp. 1-13.

[15] C. Li, S. Wu, Z. Chen, G. Tao, and Y. Xiao, "Improved microwave heating and healing properties of bitumen by using nanometer microwave-absorbers," Construction and Building Materials, vol. 189, no. 20, pp. 757-767, 2018.

[16] K. Patchai Murugan, M. Balaji, S. Swaroopa Kar, S. Swarnalatha, and G. Sekaran, "Nano fibrous carbon produced from chromium bearing tannery solid waste as the bitumen modifier," Journal of Environmental Management, vol. 270, Article ID 110882, 2020.

[17] S. N. A. Jeffry, R. Putra Jaya, N. Abdul Hassan, H. Yaacob, M. Z. H. Mahmud, and Z. H. Al-Saffar, "The influence of nano-carbon from coconut shell ash as modifier on the properties of bitumen," Road Materials and Pavement Design, vol. 2020, no. 4, 17 pages, Article ID 1809502, 2020.

[18] A. Akbari and A. Modarres, "Fatigue response of hma containing modified bitumen with nano-clay and nano-alumina and its relationship with surface free energy parameters," Road Materials and Pavement Design, vol. 2018, Article ID 1553733, 24 pages, 2018.

[19] A. A. Hussein, R. P. Jaya, H. Yaacob, N. A. Hassan, and M. Hasan, "Physical, chemical and morphology characterization of nano ceramic powder as bitumen modification," International Journal of Pavement Engineering, vol. 2, pp. 114, 2019.

[20] X. Shi, L. Cai, W. Xu, J. Fan, and X. Wang, "Effects of nanosilica and rock asphalt on rheological properties of modified bitumen," Construction and Building Materials, vol. 161, no. 10, pp. 705-714, 2018.

[21] J. Ren, S. Wang, and G. Zang, "Effects of recycled aggregate composition on the mechanical characteristics and material design of cement stabilized cold recycling mixtures," Construction and Building Materials, vol. 244, no. 3, Article ID 118329, 2020.

[22] X. Wang, J. Ren, X. Gu, N. Li, Z. Tian, and H. Chen, "Investigation of the adhesive and cohesive properties of asphalt, mastic, and mortar in porous asphalt mixtures [J]," Construction and Building Materials, vol. 276, Article ID 122255, 2021.

[23] J. Jiang, Y. Li, Y. Zhang, and H. U. Bahia, "Distribution of mortar film thickness and its relationship to mixture cracking resistance," International Journal of Pavement Engineering, vol. 2020, Article ID 1774767, 2020.

[24] C. Wang, S. Wang, Z. Gao, and Z. Song, "Effect evaluation of road piezoelectric micro-energy collection-storage system based on laboratory and on-site tests," Applied Energy, vol. 287, Article ID 116581, 2021.

[25] X. Ji, B. Han, H. Hu, S. Li, Y. Xiong, and E. Sun, “Application of the discrete element method and CT scanning to investigate the compaction characteristics of the soil-rock mixture in the subgrade," Road Materials and Pavement Design, vol. 2020, Article ID 1826350, 2020.

[26] J. Ren and C. Yin, "Investigating mechanical characteristics of aggregate structure for road materials," International Journal of Pavement Engineering, vol. 2020, Article ID 1748189, 2020.

[27] J. Huang, J. Zhang, J. Ren, and H. Chen, "Anti-rutting performance of the damping asphalt mixtures (DAMs) made with a high content of asphalt rubber (AR)," Construction and Building Materials, vol. 271, Article ID 121878, 2021.

[28] J. Huang, Y. Sun, and J. Zhang, "Reduction of computational error by optimizing SVR kernel coefficients to simulate concrete compressive strength through the use of a human learning optimization algorithm," Engineering with Computers, 2021.

[29] X. Wang, J. Ren, X. Hu, X. Gu, and N. Li, "Determining optimum number of gyrations for porous asphalt mixtures 
using superpave gyratory compactor," KSCE Journal of Civil Engineering, vol. 25, pp. 2010-2019, 2021.

[30] J. Huang, G. Shiva Kumar, J. Ren, Y. Sun, Y. Li, and C. Wang, "Towards the potential usage of eggshell powder as biomodifier for asphalt binder and mixture: workability and mechanical properties," International Journal of Pavement Engineering, vol. 2021, Article ID 1905809, 13 pages, 2021.

[31] J. Huang, G. S. Kumar, and Y. Sun, "Evaluation of workability and mechanical properties of asphalt binder and mixture modified with waste toner," Construction and Building $\mathrm{Ma}$ terials, vol. 276, Article ID 122230, 2021. 